\title{
Numerical Simulation on Stress Distribution and Deformation of Large Hydro Turbine Blade with Complex Surface during Heat Treatment Process
}

\author{
Guangnan GE ${ }^{1,2,3, \mathrm{a}^{*}}$, Lijuan ZHANG ${ }^{1,2,3, \mathrm{~b}}$, Yi LIU ${ }^{1,2,3, \mathrm{c}}$, Junfeng DING ${ }^{1,2,3, \mathrm{~d}}$, \\ Jing LI ${ }^{1,2,3, \mathrm{e}}$, Yuxin LIU ${ }^{1,2,3, \mathrm{f}}$, Shipu HOU ${ }^{1,2,3, \mathrm{~g}}$ and Daowei WEN ${ }^{1,2,3, \mathrm{~h}}$ \\ ${ }^{1}$ Harbin Research Institute of Large Electrical Machinery, Harbin, 150040, China \\ ${ }^{2}$ State Key Laboratory of Hydro-power Equipment, Harbin, 150040, China \\ ${ }^{3}$ National Engineering Research Center-Hydropower Equipment, Harbin, 150040, China \\ aclggn_0603@163.com, ${ }^{1}$ guan429@126.com, ${ }^{c}$ liuyi-hec@sohu.com, ${ }^{\mathrm{j}}$ jsnz@sina.com, \\ 'lijing_2651@163.com, ${ }^{\mathrm{f}}$ liuyx_hec@163.com, ${ }^{\mathrm{g}} 13936283233 @ 163 . c o m$, \\ hendaowei@hec-china.com
}

\begin{abstract}
A three dimensional finite element model of the heat treatment process of ZG06Cr13Ni4Mo stainless steel was established in this paper. The distribution of stress and deformation for large hydro turbine blade with complex surface during normalizing and tempering treatment has been simulated. The simulated results are consistent with the measured equivalent stress values by hole-drilling method, which indicates that the model is effective to predict the stress distribution of heat treated ZG06Cr13Ni4Mo material. Based on this model, the distribution law of stress field and deformation of the large hydro turbine blade of complex surface after the heat treatment were simulated. The established model provided a theoretical prediction method for designing of optimized complex surface blade and formulating a reasonable heat treatment process.
\end{abstract}

\section{Introduction}

Traditional martensite stainless steels have been widely used due to their high strength. However, poor corrosion resistance and bad welding properties have limited their application in some cases. Recent years, ZG06Cr13Ni4Mo martensite stainless steel with ultra-low carbon content has been developed with high strength, good plasticity, toughness, high fracture mechanics, weld ability and excellent anti-abrasive corrosion properties ${ }^{[1 \sim 4]}$. Due to these excellent properties, ZG06Cr13Ni4Mo martensitic stainless steel has been widely used to manufacture large hydro turbine blades and runners of the hydro power station such as the Three Gorges, Gezhouba power station, and etc. As the surface of large hydro turbine blade is always very complex, during heat treatment process, residual stress generally occurs, which leads to deformation of the blade. Furthermore, as the deformation of the heat treated blade cannot be predicted exactly, machining allowance

*Corresponding author:clggn_0603@163.com 
has to be increased, which causes lower production efficiency, longer producing cycle and higher producing cost ${ }^{[5,6]}$.

Researches on the design idea, the effective of main elements and heat treatment, microstructure and properties of $\mathrm{Cr} 13-\mathrm{Ni}$ series stainless steel alloy have been carried out extensively, part of which mainly focus on the operating condition of heat treatment or casting processes ${ }^{[7-20]}$. However, few researches have addressed on the simulation of the stress and deformation of the complex surface blade using FEM method. Prediction on the distribution of equivalent stress and deformation of the complex surface by FEM method would be considerably helpful for reducing the machining allowance.

In this paper, three dimensional finite element models of the heat treatment process of ZG06Cr13Ni4Mo stainless steel will be established to predict the distribution of equivalent stress and deformation of the complex surface. And then the simulated distribution of equivalent stress and deformation will be compared with the measured values, which provides a theoretical basis for optimally designing complex surface blade and formulating a reasonable heat treatment process.

\section{Experimental Materials and Methods}

In this paper, $\mathrm{X}$ type blade made of ZG06Cr13Ni4Mo for hydro turbine manufacture was researched. The maximum and minimum thickness of the blade is about $270 \mathrm{~mm}$ and $50 \mathrm{~mm}$, respectively. And the projected area of the blade is about $7.5 \mathrm{~m}^{2}$. The direct-reading spectrometer $(0800 \mathrm{H} 070003-2)$ was used to analyze the chemical composition, which is shown in table 1 . The heat treatment of the $\mathrm{X}$ type blade was performed as follows: thermal insulation of $12 \mathrm{~h}$ at $1020^{\circ} \mathrm{C}$ and then cooling in the air + thermal insulation of $14 \mathrm{~h}$ at $630^{\circ} \mathrm{C}$ and then cooling in the air+ thermal insulation of $14 \mathrm{~h}$ at $590^{\circ} \mathrm{C}$ and then cooling in the air (Normalizing + Twice tempering).

TABLE 1 CHEMICAL COMPOSITION OF ZG06CR13NI4MO STAINLESS STEEL （WT\%）

\begin{tabular}{cccccccccc}
\hline Designation & $\mathrm{C}$ & $\mathrm{Si}$ & $\mathrm{Mn}$ & $\mathrm{P}$ & $\mathrm{S}$ & $\mathrm{Cr}$ & $\mathrm{Ni}$ & Mo & Others \\
\hline ZG06Cr13Ni4Mo & 0.034 & 0.34 & 0.58 & 0.019 & 0.004 & 12.03 & 4.05 & 0.42 & 0.067 \\
\hline
\end{tabular}

The residual stress distribution on $\mathrm{X}$ type blade after heat treatment was measured using YC-III residual stress analyzer and hole-drilling method. The test point position is shown in Figure 1 and the interval between each point is $300 \mathrm{~mm}$. Coordinates of 70 points on the back of the X type blade were collected by using DT 202 three-coordinate measuring machine to monitor the deformation of blade before and after heat treatment.

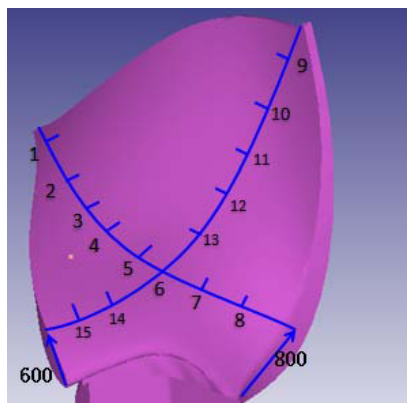

Fig. 1 Testing point position of residual stress using hole drilling method. 


\section{Establishment of Finite Element Model}

A three dimensional finite element model was established using DEFORM with mesh generation. Tetrahedral element with number of 38156 was used in the grids, and node number is 45040. Direct coupling method was used to simulate the stress and strain field. The blade material can be considered as a rigid plastic material with a slender hardening. The thermal physical performance parameters of the ZG06Cr13Ni4Mo with the temperature change are shown in Table 2.

TABLE 2 THERMAL PHYSICAL PERFORMANCE PARAMETERS OF THE ZG06CR13NI4MO [21]

\begin{tabular}{|c|c|c|c|c|c|c|c|c|c|}
\hline Temperature $/{ }^{\circ} \mathrm{C}$ & 200 & 300 & 400 & 500 & 600 & 700 & 800 & 900 & 1000 \\
\hline $\begin{array}{c}\text { Diffusion } \\
\text { coefficient } /\left(10^{-6} \mathrm{~m}^{2} \cdot \mathrm{s}^{-1}\right)\end{array}$ & 4.98 & 4.90 & 4.80 & 4.63 & 4.33 & 3.93 & 4.97 & 5.12 & 5.27 \\
\hline Specific heat $/\left(\mathrm{J} \cdot \mathrm{kg}^{-1} \cdot \mathrm{K}^{-1}\right)$ & 575 & 569 & 590 & 649 & 708 & 745 & 591 & 593 & 595 \\
\hline $\begin{array}{c}\text { Heat } \\
\text { conductivity } /\left(\mathrm{W} \cdot \mathrm{m}^{-1} \cdot \mathrm{K}^{-1}\right)\end{array}$ & 22.2 & 21.7 & 21.9 & 23.3 & 23.7 & 22.7 & 22.3 & 23.5 & 24.3 \\
\hline $\begin{array}{c}\text { Thermal } \\
\text { expansion } /\left(10^{-6} .{ }^{\circ} \mathrm{C}^{-1}\right)\end{array}$ & 11.11 & 11.86 & 11.97 & 12.40 & 12.45 & 11.43 & 8.676 & 8.654 & 10.23 \\
\hline
\end{tabular}

\section{Results of Stress Field and Deformation Simulation}

\subsection{Comparison of the simulation and measurement results of the equivalent stress field}

Fig. 2 shows the comparison results of the simulation and measurement results of the equivalent stress field of the heat treated X type blade. It is shown that the simulated equivalent stresses fall in the same order of magnitude as the measured values. The results indicate that this model would be to some extent effective and probably may be used to simulate the whole heat treatment process and to analyze the stress field and deformation.
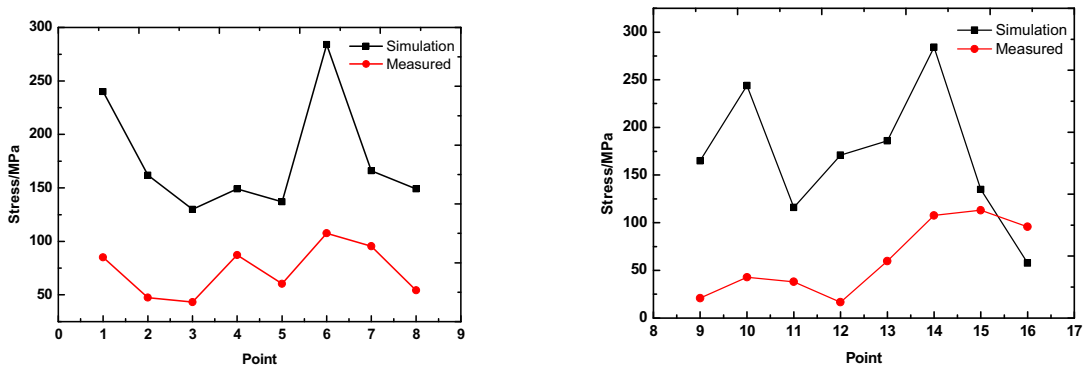

Fig.2 Comparison of simulation and measurement of the equivalent stress at different measurement points (point 13 is equal with point 6 )

\section{Numerical simulation of stress field and deformation of $X$ type blade}




\subsection{Simulation results of stress field of $X$ type blade}

Fig. 3 shows the equivalent stress distribution on the back of the $\mathrm{X}$ type blade after normalizing. It is shown that the equivalent stress distribution on the blade surface is not uniform and the value along the $\mathrm{X}$ direction of blade is larger. Along direction 1, the change of equivalent stress presents to be $M$ type and zigzag type along direction 2 . The maximum equivalent stress of $420 \mathrm{MPa}$ appears in the middle part of the blade. During cooling in the air, surface of the blade cools faster than the inner, top cools faster than bottom and edge cools faster than middle. This phenomenon causes that the temperature distribution of the whole blade is not uniform. The part cooling faster shrinks first, and at the same time, the non-shrinkage part prevents its shrinking. This causes the shrinking part products tensile stress and compressive stress on the non shrinkage part at the pre cooling. The non shrinkage part shrinks at the later period, which causes the first shrinking part products compressive stress and tensile stress on the non shrinkage part. Besides, the temperature of the part cooling faster first reduces to Ms point with its microstructure transforming from austenite to martensite. Because the heat capacity of martensite phase is bigger than that of austenite, the surface of the part cooling faster first expands. This induces that compressive stress is produced on the part with higher cooling rate, while tensile stress occurs on the part with slower rate. As the temperature decreases, the microstructure of the part with slower cooling rate begins to transform to martensite. This leads to that the part cooling faster produces tensile stress, while compressive stress appears on the part with slower cooling rate.

As the thickness of blade increases gradually from top to bottom and its shape is very complex, the cooling process and microstructure transformation of surface and inner are asynchronous, which causes the interaction between microstructure stress and thermal stress and thus complex distribution of surface and internal stress. Besides, since the edge of the blade is unconstrained while the center part constrained by surrounding material, the largest stress is generated in the center part after normalizing.

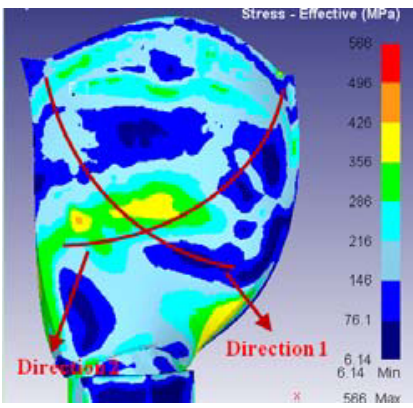

Fig.3 Equivalent stress distribution in the back of blade after normalizing

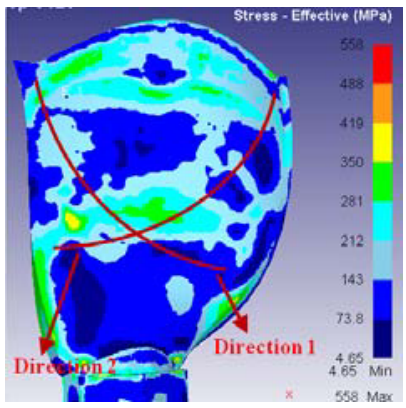

Fig.4 Equivalent stress distribution in the back of blade after normalizing and tempering 
Fig. 4 shows equivalent stress distribution on the back of blade after once normalizing and twice tempering. From the results, it can be seen that the distribution tendency of equivalent stress is almost the same with that shown in Fig.3, although the values under the current heat treatment condition are lower than those under the condition of only normalizing. The maximum value of stress, $300 \mathrm{MPa}$, also appears in the middle of the blade. As the $\mathrm{AC}_{1}$ temperature of $\mathrm{ZG} 06 \mathrm{Cr} 13 \mathrm{Ni} 4 \mathrm{Mo}$ is $578^{\circ} \mathrm{C}$, during tempering heating, the blade is affected by microstructure stress and thermal stress while only thermal stress has an impact during tempering cooling, which induces more uniformly distributed stress with a reduced amplitude during normalizing.

\subsection{Strain field of the $X$ type blade}

Fig. 5 shows the deformation distribution of $\mathrm{X}$ type blade along $\mathrm{Z}$ direction (the direction which is normal to blade surface) after once normalizing and twice tempering. The result shows that from the tailing edge to leading edge, the deformation increases firstly and then decreases, so do that from the crown side to the ring side. The deformation in $\mathrm{Z}$ direction is mainly composed of twist, which makes the blade flat. The deformation extent at tailing edge is larger than that in leading edge, and the one in ring side is larger than the extent in crown side. The biggest deformation appears at the connection of the trailing edge and the ring side, and the value is about $23 \mathrm{~mm}$. The smallest deformation appears in the middle of blade, and the value is about $1.56 \mathrm{~mm}$. Although the equivalent stress of the middle part is very large, the deformation is considerably lower due to the fact that it is constrained by surrounding material. Since the back of the blade is affected by the equivalent stress, the deformation distribution of each part of $\mathrm{X}$ type blade along $\mathrm{Z}$ direction is not uniform.

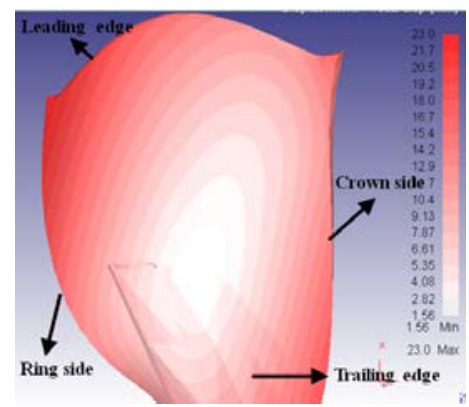

Fig.5 Deformation distribution of each part of $\mathrm{X}$ type blade along $\mathrm{Z}$ direction after heat treatment

Fig.6 shows the isoline nephogram before and after heat treatment. It can be seen that the torsion resistance of $\mathrm{X}$ type blade is large and local coordinate values, before and after heat treatment, are different from each other.

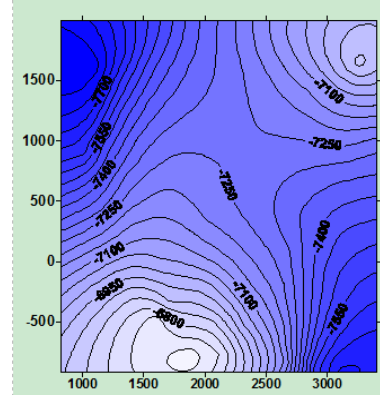

a)Before heat treatment

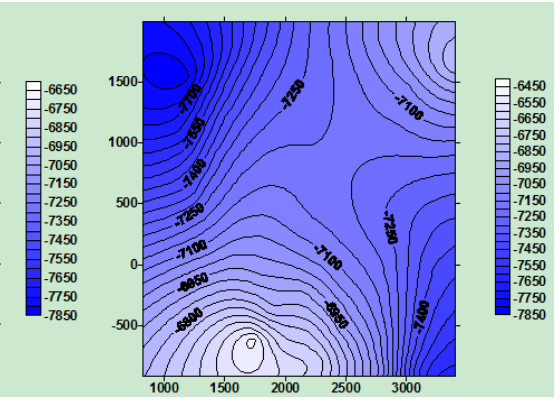

b) After heat treatment

Fig.6 Measured isoline nephogram in $\mathrm{Z}$ direction of blade before and after heat treatment 
Fig. 7 shows measured deformation distribution in $\mathrm{Z}$ direction of blade before and after heat treatment. It is shown that the measured deformation distribution is almost the same with the simulated result and the biggest deformation with a value of $26 \mathrm{~mm}$ appears at the connection of the trailing edge and the ring side further indicating the effectiveness of the current model. The deformation of the $\mathrm{X}$ type blade mainly occurs during normalizing. During the cooling process of normalizing, average linear expansion coefficient of $\mathrm{Cr} 13 \mathrm{Ni} 4$ stainless steel changes from $12 \times 10^{-6} /{ }^{\circ} \mathrm{C}$ to $-1.9 \times 10^{-6} /{ }^{\circ} \mathrm{C}$, and then to $11 \times 10^{-6} /{ }^{\circ} \mathrm{C}^{[21]}$. And the yield strength of $\mathrm{Cr} 13 \mathrm{Ni} 4$ stainless steel varies from $850 \mathrm{MPa}$ to $30 \mathrm{MPa}$. Therefore, the cooling rate and its uniformity have great influence on the deformation of the $\mathrm{X}$ type blade. For the large complex curved blade, its deformation may be reduced significantly by putting in reasonable position and adopting spray or wind cooling for the thicker part.

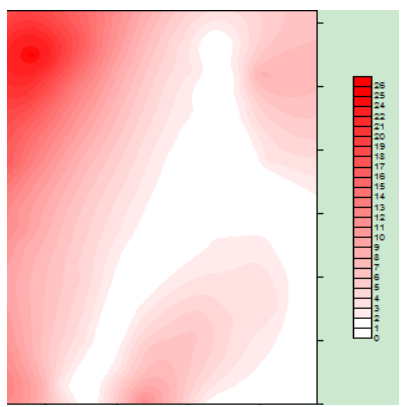

Fig.7 Measured deformation distribution in $\mathrm{Z}$ direction of blade before and after heat treatment

\section{Conclusions}

1) A three dimensional finite element model of the heat treatment process of ZG06Cr13Ni4Mo stainless steel has been established in this paper. The stress and deformation field distribution have been simulated using this model. By comparing the measured equivalent stress of the blade with the simulated values, the distribution trends are almost the same, which confirms the validity of this model.

2) The equivalent stress distribution trend of the $X$ type blade after normalizing is nearly the same with the one after normalizing and twice tempering. The equivalent stress shows zigzag law from the connection of the leading edge and the ring side to the one of the leading edge and the crown side, and $\mathrm{W}$ type law from the connection of the trailing edge and the crown side to that of the leading edge and the ring side. The biggest equivalent stress appears in the middle of blade.

3) The deformation distribution of the $X$ type blade shows $N$ type law after normalizing from the trailing edge to leading edge. The deformation at trailing edge is larger than leading edge, and ring side is larger than crown side.

4) The X type blade has the trend of being flattened after heat treatment. In order to avoid the insufficiency of finish allowance, reverse deformation should be considered when designing $\mathrm{X}$ type blade.

\section{Acknowledgments}

The authors are gratefully thanked for the financial support from China National Ocean Bureau under contract No. GHME2010CY01 and the research fund of Heilongjiang Province Postdoctoral Scientific Research Development Fund support No. LBH - Q14033. 


\section{References}

1. J. D. Crawford, K. Rohrig. A foundry success story CA-6NM [J]. Casting Engineering, 1978 (1):3-14.

2. H. J. Niederau, Engelskirchen. Present state of the development of stainless martensitic chromium nickel steels with special consideration of steel X5CrNi13-4 [J]. Stahl uEisen, 1978 (98):358-392.

3. R. Fischer,J. A. Larson. Experiences and some pitfalls in processing CA6NM [J]. American Foundry Society Transaction, 1982 (38):103-133.

4. J. A. Larson, R. Fischer. The effect of heat treatment and melt practice on the impact properties of CA-6NM steel [J]. American Foundry Society Transaction, 1979 (63): 113-126.

5. Huang Tianyou, Liu Xiaogang, et al. Present Situation and Key Technology of Large Cast Steel Production in China [J]. Casting, 2007, 56 (9): 899-904.

6. Xiang Li, et al. Deformation and Control of Heat Treatment of Hydro turbine Blade [J]. Oriental Motor, 2006 (6): 5-7.

7. Y. Iwabuchi, S. Sawada. Metallurgical characteristics of a large hydraulic runner casting of type $13 \mathrm{Cr}-\mathrm{Ni}$ stainless [C]. ASTM special technical publication. Philadelphia, 1982: 332-354.

8. Y. Iwabuchi, K. Suzuki. Study on a $13 \mathrm{Cr}-1 \mathrm{Ni}$ cast steel for a large hydraulic runner casting [J]. American Foundry Society Transaction, 1982, (41):411-422.

9. C. Hay, D. H. Patrick. Hardness conversion date for CA6NM alloy [J]. Metallograghy 1983 (16):229-233.

10. J. Hubackova, V. Cihal, K. Mazanec. Two-stage tempering of steel $13 \% \mathrm{Cr} 6 \% \mathrm{Ni}[\mathrm{J}]$. ZWerkstofftech, 1984 (15):411-415

11. H. Niinaka, A. Hirose, S. Sogabe, et al. $13 \mathrm{Cr}-3.5 \mathrm{Ni}$ martensitic steel castings for hydraulic hydro turbine runner $[\mathrm{J}]$. Kawasaki steel technical report, 1986 (14):141-151.

12. J. Svejcar, J. Hubackova, V. Cihal, et al. Austenite stabilization in Cr 13\% Ni 4-6\% steels [J]. Material technology, 1987 (58):13-17.

13. Y. Iwabuchi. Temper embrittlement of Type $13 \mathrm{Cr}-4 \mathrm{Ni}$ cast steel [J]. ISIJ international, 1987 (27):211-217.

14. Y. Iwabuchi. Effects of Nickel content and tempering treatment on the mechanical properties of low carbon martensitic stainless cast steels [J]. Transaction of Japan Foundrymen's Society, 1993; 12:69-75.

15. Y. Iwabuchi. Intergranular failure along prior austenite grain boundary of type CA6NM stainless cast steel [J]. Transaction of Japan Foundrymen's Society, 1994 (13):1-12.

16. Y. Iwabuchi. Factors affecting on mechanical properties of soft martensitic stainless castings [J]. JSME International Journal, 2003 (46):441-446.

17. Y. Y. Song, X. Y. Li, L. J. Rong, et al. Formation of the reversed austenite during intercritical tempering in a $\mathrm{Fe}-13 \% \mathrm{Cr}-4 \% \mathrm{Ni}-\mathrm{Mo}$ martensitic stainless steel [J]. Material Letters, 2010 (64): 1411-1414.

18. Y. Y. Song, D. H. Ping, F. X. Yin, et al. Microstructure evolution and low temperature impact toughness of a Fe-13\%Cr-4\%Ni-Mo martensitic stainless steel [J]. Material Science and Engineering A, 2010 (527): 614-618.

19. P. Wang, S. P. Lu, N. M. Xiao, et al. Effect of delta ferrite on impact properties of low carbon $13 \mathrm{Cr}-4 \mathrm{Ni}$ martensitic stainless steel [J]. Material Science and Engineering A, 
2010 (527): 3210-3216.

20. Y. Iwabuchi, K. Isao. A study of Toughness Degradation in CA6NM Stainless Steel [J]. Material Science Forum, 2010 (654-656):2515-2518.

21. Lu Shanping, Wang Pei. Material and welding of the Three Gorges hydro turbine runner [M]. Beijing: China Science and Technology Press, 2014. 